\title{
EXCURSO SOBRE O CONCEITO DE CONTRACULTURA
}

\author{
A. de Lima \\ Campus Natal Central - Instituto Federal do Rio Grande do Norte \\ artemilson.lima@ifrn.edu.br
}

Artigo submetido em junho/2013 e aceito em setembro/2013

\section{RESUMO}

O fenômeno da contracultura, desde a década de 1970 do século passado, tem sido objeto de vários estudos por parte de cientistas sociais, semióticos, poetas e outros estudiosos em geral. A intensa onda de rebeldia que marcou os anos de 1960, 1970 e 1980 no mundo ocidental, é sempre discutida numa abordagem dicotômica em relação ao modelo de sociedade burguesa capitalista, cuja racionalidade foi desprezada e combatida pelos beats, hippies e "descolados" que engrossavam as fileiras do que se convencionou chamar de contracultura. Este trabalho aborda a contracultura numa outra perspectiva e aponta para a possibilidade de compreendermos a esse fenômeno como resultado da dinâmica da própria cultura, sendo parte do necessário comportamento desviante que movimenta e transforma criativamente os cenários pelos quais as culturas se expressam, como parte deles também. Apoiamos nossa reflexão em autores como Roszak (1972); Maciel (1985); Pereira (1985); Bauman (1988; 2012), entre outros.

PALAVRAS-CHAVE: Contracultura. Cultura. Juventude. Sociedade Burguesa.

\section{EXCURSUS ON CONCEPT COUNTERCULTURE}

\begin{abstract}
The counterculture phenomenon, since the last century 1970 s, has been the subject of several studies by social cientists, semiotic, poets and other scholars. The intense rebellion wave that marked the 1960s, 1970s and 1980s on the western world, is always discussed in a dichotomous approach related to bourgeois capitalist society model, whose racionality was despised and countered by "beats", "hippies" and "cool people" that swell the ranks of the conventionally called counterculture. This job addresses the couterculture
\end{abstract}

another perspective and point to the possibility of understanding this phenomenon as a result of the dinamic of their owner culture, being part of the required deviant behavior that moves and transforms creatively scenarios by which cultures express themselves also as part of them. We support our reflection on authors such as Roszak (1972), Maciel (1985), Pereira (1985), Bauman (1988, 2012), among others.

KEYWORDS: Counterculture. Culture. Youth. Bourgeois Society. 


\section{EXCURSO SOBRE O CONCEITO DE CONTRACULTURA}

\section{INTRODUÇÃO}

No contexto da reorganização do mundo no pós Segunda Guerra Mundial, emerge, ainda no final da década de 1940 e se estende décadas adiante, um conjunto de ideias em torno de um imaginário carimbado pelas mazelas do malogro político e econômico dos sistemas entrincheirados nos fronts geopolíticos e ideológicos, que foram característicos e que se banalizaram nos manuais de história como Guerra Fria. Nesse cenário, um veículo derrapa, sai do asfalto e resolve manter a rota independente pelas marginais. Dentro dele, uma legião de crentes em outro modo de vida, oposto ao que consideravam a miséria humana legada pela industrialização, pelo estabelecimento de padrões de relacionamento baseados no garbo da acumulação material e do enquadramento das mentes tangidas como bois para a grande apoteose do consumo. Para designar esse fenômeno, cunhou-se a expressão "contracultura".

Essa temática, já bastante estudada, reveste-se de um fascínio provocador e instigante, pois é sempre abordada sob um viés épico e faz parte da eloquência literária, poética e artística de maneira geral, principalmente, porque é um fenômeno que, de certa forma, foi apropriado pelos intelectuais da cultura como um passaporte para a legitimação do discurso, supostamente forjador daquilo que se nos apresenta como manifestação cultural e estilo de vida à margem do que foi definido como aceitável pela sociedade tecnocrata.

Este trabalho pretende discutir o conceito de contracultura no âmbito da provocação. É um raso apanhado bibliográfico de alguns estudiosos da cultura e da contracultura, urdidos em torno da pretensa ideia de propor, quem sabe, um debate sobre o conceito de um fenômeno já, para muitos, tão distante, mas que ainda motiva defesas e reflexões.

Usamos como referenciais básicos, pensadores da cultura como Bauman $(1998 ; 2005)$ e através dele Lévi-Strauss; Paris (2002) e como autores da contracultura, Roszak (1972); Pereira (1985); entre outros.

Reforçamos a ideia de que se trata de um esboço a partir do qual julgamos serem possíveis desdobramentos teóricos mais consistentes e conclusivos.

\section{CONTRACULTURA}

Do final da década de 1950 até fins da década de 1960, em alguns países do mundo ocidental - sobretudo da Europa e nos EUA -, um fenômeno pouco heterogêneo em termos de modo de existir, mas bastante heterogêneo nos referenciais que lhe davam esteio, disseminou discursos e forjou práticas que o situaram no campo da contestação às formas de relacionamento vigentes. Esse movimento ficou conhecido como contracultura.

A maioria dos teóricos que se dedicou a estudar as nuances das manifestações desse fenômeno, situam sua origem na década de 1950. Pereira (1985) afirma que as manifestações que começam a delinear o que depois vai ser categorizado como contracultura, já eram anunciadas nos EUA, na década de 1940 quando os primeiros uivos da geração beat generation começam a serem ouvidos. 
Os marcos, segundo esses autores, entre eles Roszack (1969), seriam o lançamento do poema Howl (uivo) de Allen Ginsberg em 1956, e o aparecimento do rock'in roll sintetizado na provocativa figura de Elvis Presley. A partir daí, uma conjunção de fenômenos que reuniam manifestações coletivas e individuais que desafiavam o que se considerava cultura da tecnocracia (establishment), viria derramar, sobre a sociedade ocidental, uma profusão de comportamentos que variava de acordo com o contexto, mas que, de modo geral, abrigava-se no imenso guardachuva do que se chamou contracultura: festivais de música (woodstock, Monterrey, Ilha de Wight), debandada hippie, criação de comunidades, adoção de linguagem diferenciada, figurino descolado, culto ao transcendental e admiração pela cultura oriental, experiências com drogas alucinógenas e viagens intermináveis pelo mundo, parece que afirmavam para a sociedade tecnocrata capitalista que outro mundo era possível.

É muito importante pontuar que, embora visto como um fenômeno drop out, para o qual a família e a tradição davam de ombros, havia em torno da contracultura um arcabouço intelectual diversificado. Além da poesia e da literatura, de Kerouac, Ginsberg, Alan Watts, do psicodelismo musical das bandas de rock progressivo, como Pink Floyd, Yes, entre tantas, e das reflexões existenciais de Bob Dyllan, apoiava-se em diversas vertentes do pensamento ocidental contemporâneo.

Convém assinalar a presença de pensadores importantes como o marxista Hebert Marcuse e o psicanalista Norman Brown além de líderes vinculados às experiências do uso de drogas alucinógenas como Timothy Leary, que figuravam na lista de vivências da maioria dos jovens convertidos a essa experiência histórica.

Os campos de expressão mais abertos à divulgação dessas ideias eram os da arte cinema, música, artes plásticas, literatura e poesia - que se tornaram os principais veículos a partir dos quais mobilizavam-se mentes e corpos na busca de uma sociedade livre da alienação do consumo, das guerras e da política como instrumento de dominação.

Um aspecto particular vai marcar a ação dos grupos situados nessa epopeia social: a perspectiva diferenciada entre os grupos políticos e os desbundados. Porém, ainda que separados, em algum momento, se reconheciam como movidos pelo sentimento de que "os caminhos 'tradicionais' da transformação social estavam bloqueados, de que as velhas estratégias já não tinham a oferecer" (RISÉRIO, 2005, p. 25)

Apesar da crítica às formas tradicionais de existência da política - mesmo as de esquerda - a feição da contracultura será assumida também por uma parcela de jovens que militavam nas fileiras da esquerda marxista. E sua atuação será marcada por uma diferença quando se analisam as posturas europeias em relação às posturas norte-americanas.

Ao descrever essas diferenças, Roszack (1972) afirma que a performance dos jovens americanos difere da performance dos jovens europeus, que assumem as bandeiras da contracultura, mas não conseguem livrar-se da influência do marxismo tradicional.

Em toda a Europa Ocidental repete-se o mesmo quadro: os estudantes talvez abalem suas sociedades; mas sem o apoio das forças sociais adultas são incapazes de demolir a ordem estabelecida. [...] cantam a internacional, desfraldam a bandeira vermelha a afixam nas barricadas retratos de heróis marxistas, antigos e novos. (ROSZACK, 1972, p. 16)

Já para os jovens americanos, aparentemente, ainda que as questões de fundo político e social exigissem uma tomada de posição mais radical, era preciso enfrentar um inimigo maior, 
que não se situava apenas no campo concreto da guerra do Vietnã do racismo e da pobreza: era preciso superar a tecnocracia. Para Roszack (1972, p.19):

\begin{abstract}
A juventude americana parece haver percebido mais depressa que na luta contra esse inimigo, as táticas convencionais de resistência politica ocupam posição marginal em grande parte restrita a crises imediatas de vida ou morte. Para além dessa questões imediatas, entretanto, jaz a tarefa maior de alterar todo o contexto cultural em que tem lugar a política cotidiana.
\end{abstract}

Chegamos, aqui, no ponto em que a necessidade de compreender a contracultura, impõe trilhar o caminho de aprofundamento do seu conceito em alguns autores, incluindo, aí, esses já citados.

Comecemos por alguns autores brasileiros como Luís Carlos Maciel, em suas oito anotações sobre o conceito de contracultura na Revista Careta, citado por Pereira $(1985$, p.16), cujas formulações defendem que:

[...] o surgimento e o desenvolvimento do que se chamou contracultura não foram previstos - e só precisamente apreendidos, à custa de distorções - pelos quadros de conhecimento elaborados por nossa cultura.

Sua fonte foi a magia fundamental da realidade, seu poder incessante de criação, insubmisso a todos os tipos e tentativas de racionalização.

A nossa opção por esse trecho da anotação de Maciel, justifica-se porque nesse ponto da conceituação do fenômeno da contracultura, ele se coaduna com a defesa do conceito elaborado pelo principal pensador do fenômeno, aqui já apresentado: o sociólogo americano Theodore Roszak, em sua obra intitulada "A Contracultura", que inaugura uma teorização do fenômeno no campo da sociologia e que servirá de referência principal para boa parte dos escritos sobre o tema. É provável que, mesmo considerando a autonomia de pensamento de Maciel, este tenha lido o segundo e tenha sido por ele influenciado.

O que aproxima a reflexão de Maciel das reflexões de Roszak, é a tese de que o principal alvo da contracultura era o combate às formas de expressão da sociedade burguesa tecnocrata, ou mais diretamente à tecnocracia, incluindo aí a própria racionalidade científica herdada da modernidade iluminista. Na visão de Roszak (1972, p. 22), a tecnocracia como modelo negado e combatido pela contracultura, consiste na "forma social na qual a sociedade industrial atinge o ápice de sua integração organizacional". Para o autor, ela, a tecnocracia, consolida-se como um "fenômeno transpolítico" enquanto os agentes da sociedade organizam e prosseguem com o debate político. Nesse sentido, a tecnocracia projeta-se mais como um imperativo cultural imponente, incontestável e indiscutível que será questionado e recusado pelos jovens da contracultura.

Ainda que esses elementos sejam definidores do termo contracultura, no contexto histórico que até o momento descrevemos, e mesmo sendo esse contexto o momento em que o termo foi cunhado para designar o conjunto de manifestações do fenômeno, convém sublinhar que outros tipos de manifestações juvenis em outros contextos históricos, poderiam ser encaixados nessa concepção. Analisando as oito anotações de Maciel, Pereira (1985) assinala que se pode empregar o termo contracultura para designar um fenômeno mais geral, mais anárquico, que reaparece de tempos em tempos e em diferentes épocas, parece ter um espírito revigorador da crítica social. 
Essa visão é reforçada por Sevcenko (2005), para quem o impulso para a crítica social data da primeira geração romântica na França, no contexto das agitações que se seguiram às turbulências da revolução Francesa e se desdobra nas atitudes dos jovens poetas notívagos, beberrões e arruaceiros que desprezam e criticam os bons modos de sua época. As atitudes de violação ao status quo prosseguem em outros momentos e assumem forma de confronto utilizando-se, sobretudo, da arte, para dar visibilidade às novas ideias. Um momento bem flagrante é o movimento modernista europeu que se afirma, principalmente, na arrogância irresponsável de pintores, poetas, escritores e amantes da arte de maneira geral.

No Brasil, o que se configurou como contracultura, as manifestações contra o modelo de sociedade vigente, ganha contornos diferenciados. Em primeiro lugar, porque acontece tardiamente, quando comparado aos movimentos europeus e norte-americanos. Nessa perspectiva, enquanto os arautos da rebeldia jovem norte-americana e europeia vaticinavam o "fim do sonho", é que começam as escaramuças da juventude brasileira, cujo ânimo antiintelectualista era alimentado pela tradição pragmática dos norte-americanos (RISÉRIO, 2005), ao mesmo tempo em que estava, também, incumbida do sentimento de oposição, resistência e rompimento com chamada modernização autoritária imposta pelo estado militar a partir do golpe de 1964. (COELHO, 2005)

Um aspecto particular vai marcar a ação dos grupos situados nessa epopeia social no Brasil: a perspectiva diferenciada entre os grupos políticos e os desbundados. Porém, ainda que separados, em algum momento, se reconheciam como movidos pelo sentimento de que "os caminhos 'tradicionais' da transformação social estavam bloqueados, de que as velhas estratégias já não tinham a oferecer". (RISÉRIO, 2005, p. 25)

Para o primeiro grupo, o político, a saída, era a luta armada, a guerrilha urbana, contra o estado autoritário, enquanto que o segundo, os desbundados, dirigiam suas energias para o questionamento dos fundamentos desse estado: a racionalização da vida social.

O caráter pluridimensional dessa prática social aparecia nas suas principais características: a ênfase a subjetividade em oposição ao caráter objetivo racional do mundo exterior, a aproximação com a loucura e a marginalidade, a construção de comunidades alternativas. (COELHO, 2005, p. 39)

Interessante notar que, mesmo essa oposição mais subjetiva às formas de dominação do estado militar, terá como resultado a repressão à liberdade de expressão e às práticas contraculturais, tão bem ilustradas na prisão de hippies, no internamento de "loucos" em hospitais psiquiátricos e no exílio.

Vê-se, portanto, como as ideias e ações que delineiam o fenômeno da contracultura tenderam a ganhar contornos diferenciados, de acordo com o contexto social em que foram lidas e incorporadas. Temos nessa breve reflexão três telas diferentes para uma mesma moldura: o caso europeu, o norte-americano (o mais expressivo) e o contexto específico brasileiro - os ecos da contracultura na periferia.

Nesse sentido, um esforço para refletir sobre o tema, a partir desses conceitos e exemplos de manifestações da contracultura, talvez exija um mergulho, ainda que raso, na perspectiva de estabelecer um diálogo do conceito de contracultura com a concepção contemporânea de cultura.

Para começar a estabelecer os canais desse diálogo, talvez fossem necessárias duas indagações: 1) o fenômeno da contracultura, independente do contexto histórico ou geográfico, 
ao questionar, negar e combater um modelo de vida consolidado pelo capitalismo ocidental, constitui-se de fato um contradiscurso totalmente distanciado desse modelo? 2) O termo em si, contracultura, enceta, de fato, uma proposta oposta à cultura no interior da qual surgiu, ou é uma possibilidade aberta pelas brechas existentes nessa cultura, sendo, portanto, dela constituinte, ainda que disposta a criticá-la?

Uma pretensa resposta a essas indagações nos obriga a buscarmos algumas concepções de cultura em alguns autores contemporâneos.

\section{CULTURA}

É sabido que o conceito de cultura, até chegar às formulações de hoje, percorreu um longo caminho desde a tradição iluminista. Uma boa contribuição para o refinamento desse conceito, foi fruto das reflexões sucessivas de antropólogos, como Edward Tylor, Alfred Kroeber, Franz Boas, Clifford Geertz, Claude-Lévi-Strauss, entre outros (LARAIA, 2006). Não convém, neste escrito, fazer uma revisão da contribuição particular de cada um deles, pois não se constitui objeto.

O fato é que a contribuição de cada um possibilitou a chegada a concepções mais elaboradas do termo cultura. Em especial, a concepção de Lévi-strauss, demarca, em definitivo, pelo menos por enquanto, uma referência importante para as reflexões contemporâneas.

Para efeito de que pretendemos aqui - compreender em que medida o conceito de contracultura, propõe uma ruptura com um modelo específico ou é uma decorrência desse modelo - nos apoiaremos inicialmente em Bauman (2012, p.296), para quem:

\footnotetext{
A cultura constitui a experiência humana no sentido de sempre enfatizar a discordância entre o ideal e o real, de tornar a realidade significativa ao expor seus limites e imperfeições, de misturar e fundir, de maneira invariável, conhecimento e interesse; ou melhor, a cultura é um modo de práxis humana em que conhecimento e interesse são uma só coisa.
}

Ao defender essa concepção de cultura, Bauman parece nos propor um caminho, cuja margem não o estreita nem o delineia. É como se estivesse nos dizendo que a compreensão do que seja cultura nos escapa, pela própria condição de sermos nós próprios os seus fazedores e que é possível que consigamos algum distanciamento do que criamos, mas estaremos sempre fundidos na criação.

Aqui Bauman toma emprestado o conceito de cultura, desenvolvido por Lévi-Strauss, em que "a cultura não é, senão, uma atividade perpétua", e que "a cultura não serve a nenhum propósito, não é uma função de nada, não há nada que ela possa avaliar objetivamente com seu sucesso ou correção". (BAUMAN, 1998, p.167)

Nesse sentido, reforça um aspecto importante da concepção straussiana, da condição caleidoscópica da cultura, quando afirma que, distante da arte da adaptação, a cultura é a mais subversiva iniciativa de separar-se das amarras da adaptação, que se constituem obstáculos a mais plena criatividade humana. (BAUMAN, 2012)

Essa dinâmica caleidoscópica, constituída por um movimento de constante amalgamação, é identificada por Paris (2002) como fenômeno para além do circunstanciamento da vida do 
sujeito, mas se expressa penetrando na vida e conferindo a ela possibilidades de subsistência e de expansão:

\begin{abstract}
Constituindo um todo dinâmico, complicado internamente por subculturas de classe, sexo, de idade, agitado por contradições e relações externas com o mundo e com outras culturas, sua análise nos dá chaves decisivas para compreender o processo histórico e o comportamento humano. (PARIS, 2002, p. 88-89)
\end{abstract}

Os três autores propõem uma reelaboração da concepção, na perspectiva de superar a concepção clássica de cultura como algo sistêmico, estruturado, normatizado. Para ambos, compreender a cultura é estar admitindo a necessidade do não normatizado, do desviante, ou seja, sempre haverá água escorrendo por entre os dedos, por mais que fechemos a mão em concha.

Apesar de rápida, a tomada que fizemos até aqui sobre cultura, nos servirá em primeira instância para iniciarmos o nosso cotejamento conceitual a fim de responder às duas questões que formulamos no final da segunda seção. Para isso, será útil uma reflexão sobre os elementos da chamada cultura contra a qual o fenômeno conhecido como contracultura se "insurge".

\title{
CONTRA QUE CULTURA?
}

Todas as análises do fenômeno da contracultura dão conta de um conjunto de manifestações que estão envoltos em um espectro de crítica social a uma cultura específica, carimbada pelo modo de ser e de se expressar da sociedade capitalista, na sua forma mais refinada de se apresentar. Maciel (1985) apela para ideia de que o surgimento da contracultura se configura uma espécie de antídoto social contra uma sociedade doente, "de nossa cultura tradicional".

Essa patologia teria sido desencadeada com o advento do industrialismo e a emergência da sociedade de consumo, por um lado; por outro, pela tradição iluminista que inaugura a racionalidade moderna, calcada no cientificismo cartesiano, que, de certa forma, alimentou e alimentou-se do primeiro sintoma. O resultado teria sido a alienação, a exploração, o autoritarismo, a repressão, paradoxalmente ao que propalavam as intensões burguesas com a ideia de que a lufada de liberdade, trazida pelo iluminismo, tiraria o homem moderno de sua fase adolescente e o traria para a maioridade.

É também nesse sentido que Roszak (1972), antes de iniciar o desfibramento do fenômeno da contracultura, desenha um cenário, aqui já apresentado como a doença da sociedade moderna e que ele resume no conceito de tecnocracia, quando afirma que "a meticulosa sistematização que Adam Smith levou em sua famosa fábrica de alfinetes estende-se hoje a todas as áreas da vida, proporcionando-nos uma organização humana que compete em precisão com nossa organização mecânica". (ROSZAK, 1972, p. 19)

Em outras palavras, a cultura a ser combatida era aquela fundada num ideal de humanismo cujo núcleo talvez possamos ousadamente ilustrar com a ideia da "fantasia de uma seita ou clube - o sonho da predestinada solidariedade dos que foram eleitos para saber ler." (SLOTERDIJK, 2000, p.10) e que, na primeira manhã da segunda metade do século passado, regurgitava a sopa do progresso na qual mergulhara, e levava essa racionalidade a ser assumida alienadamente pelas multidões de consumidores no mundo inteiro. 
Em última instância, a sociedade (ou a cultura) a ser combatida, desprezada pela juventude é a que Bauman (2012, p. 49), afirma ter sido formada no:

\begin{abstract}
limiar da modernidade onde (sic) se encontra o processo de autoformação da elite letrada ou esclarecida (que agora distingue os modos civilizados, com suas duas faces de "refinamento espiritual" e adestramento corporal), que foi, ao mesmo tempo, um processo de formação orientada das massas, como campo potencial da função, ação e responsabilidade de supervisão das elites.
\end{abstract}

Será, portanto, contra o que se configura coetaneamente como esteio desse processo de formação da cultura ocidental burguesa que se dará a sedição juvenil, decantada como contracultura, cujos resultados até hoje são objeto de reflexão.

Entretanto, atualmente, esses resultados estão diluídos e visualmente muito distantes, envoltos numa névoa, cujos elementos só são perceptíveis aos que preservam acuidade visual de quem direta ou indiretamente vivenciou de alguma forma essa experiência. A manutenção do ideal, como resistência que persiste, são apenas gotejos de pequenos grupos que insistem num comportamento out, na maioria das vezes, transformado em grifes ou melancolicamente identificados como cult. Afora uma pequena minoria de antigos que optaram por prolongar ad infinitum a experiência, a maioria dos sujeitos que a vivenciaram integrou-se total ou parcialmente ao modo tecnocrata de vida, embora deva haver, no íntimo de cada um, reminiscências que oportunamente voltam. Mas afirmar isso talvez seja trabalhar com uma subjetividade tão profunda! E isso está muito longe desta reflexão que ora nos propomos.

\title{
A CONTRACULTURA COMO CULTURA DA CULTURA
}

As reflexões realizadas até aqui não são suficientes para responder às duas questões formuladas no início do trabalho, mas, certamente, nos ajudam a refletir sobre possibilidades de respostas. Vejamos: ao primeiro questionamento, poderíamos responder que sim, posto que, se tomarmos a contracultura como fenômeno que rompe com as formas cotidianas de relacionamento e padrões na sociedade burguesa, tecnocrata, principalmente no que diz respeito à adoção de valores opostos aos dessa cultura, com certeza, vamos encontrar vários elementos que nos garantiriam afirmar que havia um distanciamento radical do discurso e das práticas contraculturais em relação a essa cultura.

Entretanto, essa facilidade de interpretação do fenômeno que distraidamente é resolvida também conceitualmente pela força intrínseca do termo que encerra um prefixo simplificador contra, que significa que se opõe e, portanto, contracultura como conjunto de manifestações que marca uma revolta contra as atividades ideológicas e artísticas dominantes (HOUAISS, 2001) - é só aparente.

Questionado numa perspectiva interpretativa em relação à concepção de cultura que definimos como referencial, essa aparente simplicidade se dissolve e nos obriga a enxergá-la num viés mais complexo.

Assim, Bauman (1998, p. 167), ao refletir sobre as três ideias orientadoras de Lévi-Strauss, na busca de um novo arcabouço dos estudos da cultura diz que:

não existe estrutura global da cultura [...] as culturas, como as sociedades, não são totalidades; [...] a cultura não é uma atividade estacionária, mas um processo [...] uma 
atividade perpétua, e a estrutura não é senão a constante manipulação de possibilidades; a cultura não serve a nenhum propósito, não é função de nada, não há nada que ela possa avaliar objetivamente com seu sucesso ou correção.

Conclui-se que essas três ideias juntas, geram uma visão de cultura que despreza as concepções de cultura como algo petrificado e enceta uma visão de cultura como ação permanentemente inquieta, transgressora, rebelde, "ao mesmo tempo ordenadora, mas, ela mesma não ordenada."

\footnotetext{
As ações não são determinadas inequivocamente - ou de forma causal, por causas precedentes ou de forma teleológica, por metas assumidas. O que ocorre de fato, é uma interação de ambos os fatores, o estado de coisas que, por si mesmo coloca um ponto de interrogação na própria ideia de determinação. (BAUMAN, 1998, p. 169)
}

Vê-se, assim, que uma análise da contracultura, como um fenômeno que propõe, de fato, uma crítica social à sociedade burguesa tecnocratizada e consegue, nos marcos de suas ações, diferenciar-se do que caracteriza essa sociedade, talvez, se interpretada à luz dessa concepção de cultura, possa ser concebida muito mais como um movimento inevitável, o resultado "desse estado de coisas que, por si mesmo coloca um ponto de interrogação" e menos como uma iniciativa que emerge como contraponto elaborado de fora e que está imunizada dos elementos da cultura que critica e combate.

Mesmo se pensarmos que a contracultura proporciona um espaço que permite visibilidade de certas manifestações artísticas e culturais que antes eram consideradas insignificantes ou mesmo desconsideradas - destaque-se aqui a cultura afrodescendente, a cultura indígena e a cultura popular, no Brasil, por exemplo (RISÉRIO, 2005) - talvez seja possível compreendê-la como um necessário movimento desviante, não ordenado, oportuno, na medida em que identifica e denuncia o espectro nefasto dos caminhos que a sociedade tomava naquele momento, sob a batuta grosseira do estado militar que, em certa medida, era representativo de uma elite, contra a qual a juventude se insurgia.

Portanto, a concepção de contracultura, se enxergada na perspectiva desse necessário desvio da cultura, não como totalidade, mas como um "todo dinâmico complicado internamente por subculturas de classe, sexo, de idade, agitado por contradições" como defende Paris (2002, p. 88), possa significar uma proposta oposta à cultura no interior da qual surgiu, muito mais como uma possibilidade aberta pelas brechas existentes nessa cultura, sendo, portanto, dela constituinte, ainda que disposta a criticá-la.

\section{CONSIDERAÇÕES FINAIS}

As reflexões aqui apresentadas talvez sejam ousadas demais, diante do que já se escreveu sobre o fenômeno da contracultura. A intenção, porém, tem caráter muito mais provocativo do que elucidativo. Os escritos sobre a contracultura, até onde conhecemos, tratam da temática, muito mais na perspectiva de situar o fenômeno como um contraponto ao modelo ocidental de sociedade num contexto histórico dado, aparentemente com forte inclinação maniqueísta. Nunca tratam dessa temática na perspectiva de situar o fenômeno da contracultura como um movimento da própria cultura, não como totalidade, mas como o resultado de um estado de coisas que estão perpetuamente exigindo o desvio, como fator propulsor do giro necessário do 
caleidoscópio que oferece, a quem observa, sempre uma profusão de formas diferentes, por mais que no interior do objeto as contas de vidro sejam poucas, porém, uma vez refletidas e rerefletidas pelos espelhos, propõem uma diversidade infinita de formas. Giremos, pois, esse objeto.

\section{REFERÊNCIAS BIBLIOGRÁFICAS}

BAUMAN, Zigmunt. Ensaios sobre o conceito de cultura. Tradução de Carlos Alberto Medeiros. Rio de Janeiro: Zahar, 2012.

O mal-estar da pós-modernidade. Tradução de Mauro Gama. Claudia Martinelli Gama. Rio de Janeiro: Zahar, 1998.

COELHO, Claudio Novaes Pinto. Contracultura: o outro lado da modernização autoritária. In: Anos 70: trajetórias. São Paulo: lluminuras; Itaú Cultural. 2005.

HOUAISS, Antonio; VILLAR, Mauro de Salles; FRACO, Francisco Manoel de Mello. Dicionário Houaiss da língua portuguesa. Rio de Janeiro: Objetiva, 2001.

LARAIA, Roque de Barros. Cultura: um conceito antropológico. Rio de Janeiro: Zahar, 2006.

PARIS, Carlos. 0 animal cultural: biologia na realidade humana. Tradução de Marly Almeida Gomes Vianna. São Carlos: EDUFSCAR, 2002.

PEREIRA, Carlos Alberto M. O que é contracultura. Rio de Janeiro: Brasiliense, 1985. (Coleção Primeiros Passos).

RISÉRIO, Antônio. Duas ou três coisas sobre a contracultura no Brasil. In: COELHO, Claudio Novaes Pinto. Anos 70: trajetórias. São Paulo: Iluminuras; Itaú Cultural. 2005.

ROSZAK, Theodore. A contracultura. Tradução de Donaldson M. Garschagen. Rio de Janeiro: Vozes, 1972.

SEVCENKO, Nicolau. Configurando os anos 70: a imaginação no poder e a arte nas ruas. In: COELHO, Claudio Novaes Pinto. Anos 70: trajetórias. São Paulo: Iluminuras; Itaú Cultural. 2005.

SLOTERDIJK, Peter. Regras para um parque humano. Tradução de José Oscar de Almeida Marques. São Paulo: Estação Liberdade, 2000. 